Linköping Studies in Science and Technology

Thesis No. 1809

\title{
Optimization of Vehicle Structures under Uncertainties
}

\author{
Sandeep Shetty
}

I..U U⿴囗十)

\author{
Division of Solid Mechanics \\ Department of Management and Engineering \\ Linköping University \\ SE-581 83 Linköping, Sweden
}

Linköping, January 2017 
Cover:

Schematic illustration of robustness analysis. The histograms indicate the variations in input parameter $x$ and the output parameter $f$ respectively.

The front cover picture is reproduced by courtesy of Volvo Car Corporation and illustrates a side impact simulation.

Printed by:

LiU-Tryck, Linköping, Sweden, 2017

ISBN 978-91-7685-630-7

ISSN 0345-7524

Distributed by:

Linköping University

Department of Management and Engineering

SE-581 83 Linköping, Sweden

\section{(C) 2017 Sandeep Shetty}

No part of this publication may be reproduced, stored in a retrieval system, or be transmitted, in any form or by any means, electronic, mechanical, photocopying, recording, or otherwise, without prior permission of the author. 


\section{Preface}

The work presented in this thesis has been carried out at the Division of Solid Mechanics Linköping University in collaboration with Volvo Car Group. Financial support has been provided by the 'Robust and multidisciplinary optimization of automotive structures' Project funded by Vinnova FFI, Volvo Car Group and the ProViking/ProOPT Project funded by SSF.

This thesis could not have been completed without the support of numerous individuals. First and foremost, I would like to express my deepest appreciation to my supervisor, Professor Larsgunnar Nilsson for his guidance and support during the course of this work. I am very grateful to my supervisors at Volvo Car Group Kaj Fredin and Dr. Alexander Govik for their constant support and guidance. I would especially like to thank my former industrial supervisors Dr. Mikael Fermér and Dr. Harald Hasselblad for their guidance towards my Licentiate degree.

I would also like to thank all my colleagues at the university and at Volvo Cars, especially Dr. Johan Jergéus and Henrik Ebbinger for their support during my work. I thank all the representatives of the industrial partners in this project, especially David Aspenberg (Dynamore) for his valuable feedback and Christoffer Järpner (Enginsoft) for his technical assistance during the project.

Finally, I would like to thank my friends and family. Without you I could not have completed this. A special thanks to my lovely wife Manini for her support and encouragement. I dedicate this work to my mother Sumitra who has been great source of inspiration and my daughter Anika for making my everyday life more joyful.

Göteborg, January 2017

Sandeep Shetty 


\section{Abstract}

Advancements in simulation tools and computer power have made it possible to incorporate simulation-based structural optimization in the automotive product development process. However, deterministic optimization without considering uncertainties such as variations in material properties, geometry or loading conditions might result in unreliable optimum designs.

In this thesis, the capability of some established approaches to perform design optimization under uncertainties is assessed, and new improved methods are developed. In particular, vehicle structural problems which involve computationally expensive Finite Element (FE) simulations, are addressed.

The first paper focuses on the evaluation of robustness, given some variation in input parameters, the capabilities of three well-known metamodels are evaluated. In the second paper, a comparative study of deterministic, reliability-based and robust design optimization approaches is performed. It is found that the overall accuracy of the single-stage (global) metamodels, which are used in the above study, is acceptable for deterministic optimization. However, the accuracy of performance variation prediction (local sensitivity) must be improved. In the third paper, a decoupled reliability-based design optimization (RBDO) approach is presented. In this approach, metamodels are employed for the deterministic optimization only while the uncertainty analysis is performed using FE simulations in order to ensure its accuracy.

In the fifth paper, two new sequential sampling strategies are introduced that aim to improve the accuracy of the metamodels efficiently in critical regions. The capabilities of the methods presented are illustrated using analytical examples and a vehicle structural application.

It is important to accurately represent physical variations in material properties since these might exert a major influence on the results. In previous work these variations have been treated in a simplified manner and the consequences of these simplifications have been poorly understood. In the fourth paper, the accuracy of several simple methods in representing the real material variation has been studied. It is shown that a scaling of the nominal stress-strain curve based on the $\mathrm{R}_{\mathrm{m}}$ scatter is the best choice of the evaluated choices, when limited material data is available.

In this thesis work, new pragmatic methods for non-deterministic optimization of large scale vehicle structural problems have been developed. The RBDO methods developed are shown to be flexible, more efficient and reasonably accurate, which enables their implementation in the current automotive product development process. 


\section{Sammanfattning}

Programvaruutveckling och ökad datorkapacitet har gjort det möjligt att integrera simuleringsbaserad strukturoptimering i bilindustrins utvecklingsprocess. Konventionell deterministisk optimering, utan beaktande av osäkerhet och variation i materialegenskaper, geometri och lastvillkor, kan dock leda till otillförlitliga strukturer.

I den här avhandlingen har ett antal etablerade metoder för att genomföra designoptimering med beaktande av osäkerhetsfaktorer utvärderats och nya förbättrade metoder har utvecklats. Fokus för studien har varit fordonsstrukturer där stora och komplexa Finita Element (FE) modeller används, vilka kräver omfattande datorberäkningar.

Den första artikeln i avhandlingen behandlar utvärderingen av en konstruktions robusthet, där en viss variation i indataparametrar förutsatts. Prediktionsförmågan hos tre välkända metamodellsformuleringar har bedömts. En metamodell är en matematisk approximation av en respons baserad på utvärderingar i ett antal designpunkter. I den andra artikeln har en jämförande studie av tre olika optimeringsformuleringar utförts avseende deterministisk, tillförlitlighets- och robusthetsbaserad optimering. Studien visar att globala metamodeller, d.v.s. en metamodell för hela designrymden, ger tillräcklig noggrannhet vid deterministisk optimering men att noggrannheten måste förbättras för att kunna utvärdera den lokala känsligheten. I den tredje artikeln presenteras en metod för okopplad tillförlitlighets-baserad optimering (Reliability-based design optimization, RBDO). I metoden används metamodeller endast för ett deterministiskt optimeringssteg medan osäkerhetsanalysen genomförs lokalt med FE-simuleringar i avsikt att säkerställa noggrannheten.

I den femte artikeln har två nya sekventiella metoder för RBDO presenterats, vilka inriktar sig på att förbättra metamodellers noggrannhet i kritiska områden. De presenterade metodernas duglighet illustreras genom analytiska exempel och i en tillämpning innefattande en fordonsstruktur.

Vid icke-deterministisk optimering är det viktigt att korrekt beskriva den fysiska variationen i materialegenskaper. I tidigare arbeten har materialegenskapsvariationer hanterats på ett förenklat sätt, men konsekvenserna av förenklingarna har sällan studerats. I den fjärde artikeln har noggrannheten hos flera enkla metoder för att representera den fysiska materialegenskapsvariationen studerats. Studien visar att när tillgänglig materialdata är begränsad, vilket vanligen är fallet i tidiga produktutvecklingsskeenden, är en skalning av den nominella dragprovskurvan baserat på spridning i $R_{m}$ det bästa alternativet av de undersökta.

I denna avhandling har nya pragmatiska metoder för icke-deterministisk optimering av storskaliga strukturanalyser utvecklats. Metoderna har visat sig vara flexibla, noggranna och effektiva, vilket möjliggör deras implementation i dagens produktutvecklingsprocess i bilindustrin. 


\section{List of Papers}

In this thesis, the following papers have been appended:

I. S. Shetty, L. Nilsson (2016), Robustness study of a hat profile beam made of boron steel subjected to three point bending, International Journal of Vehicle Systems Modelling and Testing, Volume 11, Issue 3, pp. 252-270.

II. S. Shetty, L. Nilsson (2015), Multiobjective reliability-based and robust design optimisation for crashworthiness of a vehicle side impact, International Journal of Vehicle Design, Volume 67, Issue 4, pp. 347-367.

III. S. Shetty (2014) 'Efficient reliability-based optimization using a combined metamodel and FE-based strategy'. In Proceedings: 4th International Conference on Engineering Optimization (EngOpt), Lisbon, Portugal.

IV. S. Shetty, L. Nilsson (2016), An evaluation of simple techniques to model the variation in strain hardening behavior of steel, Structural and Multidisciplinary Optimization, DOI:10.1007/s00158-016-1547-6.

V. S. Shetty, A. Govik, L. Nilsson (2016), Two sequential sampling methods for metamodeling in reliability-based design optimization, Submitted.

Author's contribution

I have borne the primary responsibility for all parts of the work presented in the papers. All papers were primarily written by me, with support from my co-authors. 


\section{Contents}

Preface $\quad$ iii

Abstract $\quad$ v

Sammanfattning vii

$\begin{array}{ll}\text { List of Papers } & \text { ix }\end{array}$

Contents $\quad x i$

1. Introduction 3

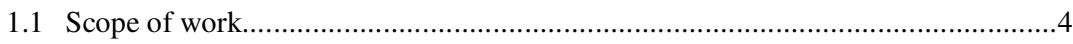

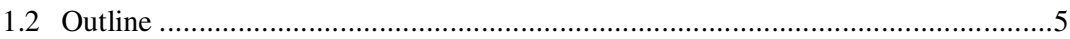

$\begin{array}{ll}\text { 2. Uncertainty analysis } & 7\end{array}$

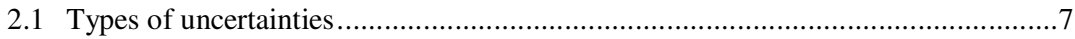

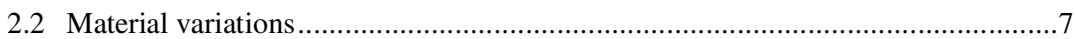

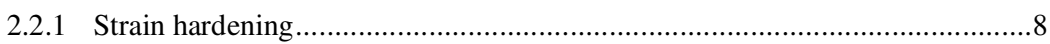

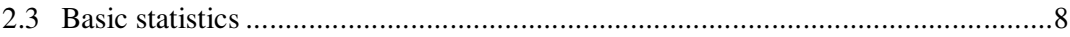

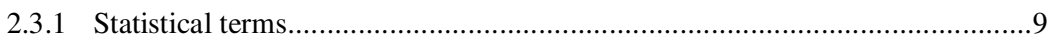

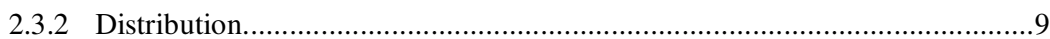

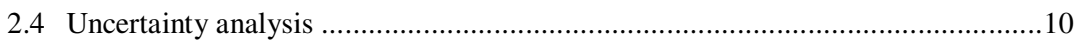

2.4.1 Mean value first-order second-moment method (MVFSOM) ........................11

2.4.2 MPP-based methods...............................................................................12

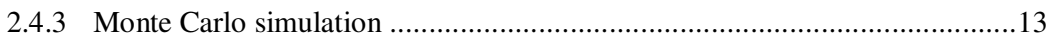

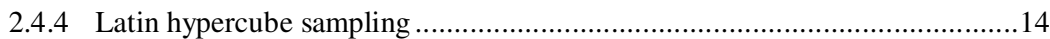

2.4.5 Worst-case approach and moment matching formulation ............................15

3. Structural optimization $\quad 17$

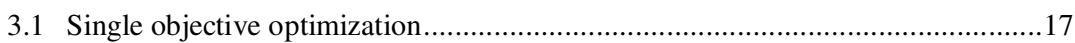

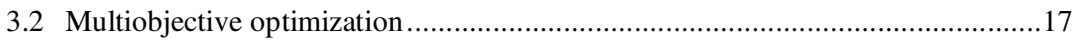

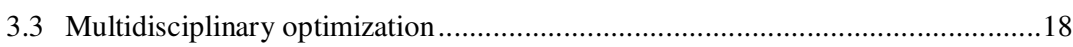


4. Metamodel-based design optimization 21

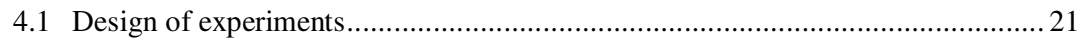

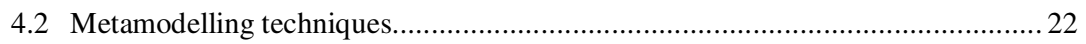

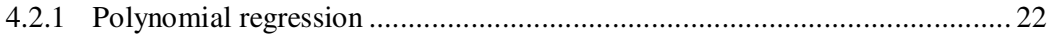

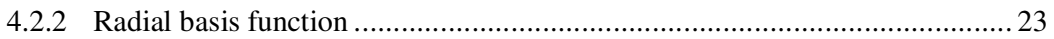

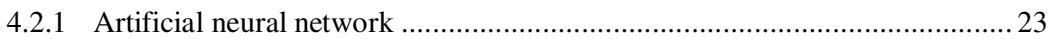

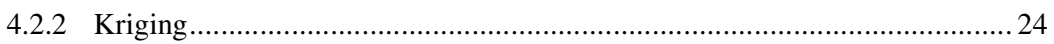

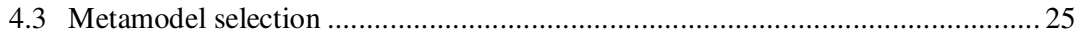

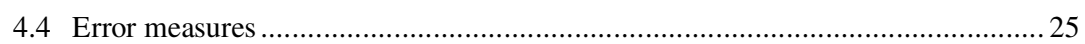

5. Stochastic optimization $\quad 27$

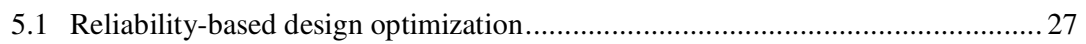

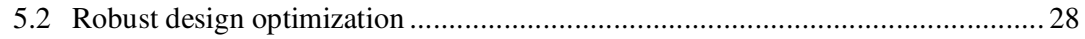

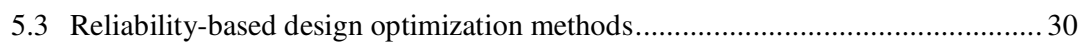

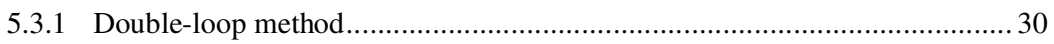

5.3.2 Decoupled methods ................................................................................... 30

5.3.3 Single-loop methods.............................................................................. 30

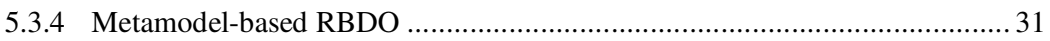

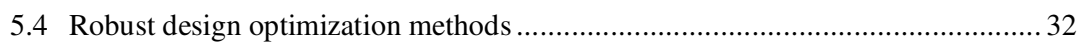

6. Review of appended papers 33

$\begin{array}{ll}\text { 7. Conclusions and outlook } & 37\end{array}$

$\begin{array}{ll}\text { Bibliography } & 41\end{array}$

Appended Papers $\quad 45$

Paper I: Robustness study of a hat profile beam made of boron steel subjected to three point bending

Paper II: Multiobjective reliability-based and robust design optimization for crashworthiness of a vehicle side impact.

Paper III: Efficient reliability-based optimization using a combined metamodel and FE-based strategy

Paper IV:An evaluation of simple techniques to model the variations in strainhardening behavior of steel.....

Paper V: Two sequential sampling methods for metamodeling in reliability-based design optimization. 
Part I

\section{Theory and background}





\section{Introduction}

In the automotive industry, the time to market has been significantly reduced in recent years. Simulation-based design processes play a vital role in reducing the product development cycle time. Advancements in computational power and efficient algorithms have made the simulation-based design process faster and more efficient, and also made it possible to include structural optimization. Furthermore, increased safety requirements and emission targets have led the automotive industry to focus on developing light-weight body structure design without compromising performance level. Consequently, the use of simulation-based design optimization in the product development process is increasing in order to achieve this target. Conventional deterministic optimization methods do not incorporate uncertainties. The optimum design obtained under deterministic conditions might be sensitive to input variations such as variations in material properties, geometry or loading conditions. Previously, the effect of these uncertainties was minimized by using high level safety factors. However, often these safety factors negatively affect weight efficiency. Consequently, it is necessary to consider the variations in input variables during optimization in order to identify designs that can handle uncertainties without failing to fulfil performance requirements.

Several, non-deterministic optimization methods have been reported in literature that explicitly incorporate uncertainties into the optimization process. These methods can be classified into two main categories, reliability-based design optimization (RBDO) and robust design optimization (RDO). The primary aim of RBDO is to identify optimum designs which have a low probability of failure under uncertainties. Robust design optimization aims at finding optimum designs that are less sensitive to variations. Robust design optimization in general also aims at restricting the probability of failure to a minimum. The robust design concept was originally introduced by Genichi Taguchi (Taguchi 1993). The main aim of Taguchi's method is to minimize the performance variations caused by input variations, without eliminating the causes of these variations. Taguchi's method was originally developed for experimental studies and does not use a systematic optimization process.

Traditionally, double-loop methods have been used to perform stochastic optimization, i.e. the inner loop is used for the uncertainty analysis and the outer loop for the optimization. The uncertainty analysis is performed to determine the variation of responses. Double-loop 
methods are prohibitively expensive for large scale problems. Several studies have focused on improving the efficiency of stochastic optimization methods (Parkinson et al. 1993; Lee and Park 2001; Wu et al. 2001; Du and Chen 2004; Liang et al. 2004; Shan and Wang 2008), either by improving the efficiency of the optimization process or by modifying optimization formulations. Some researchers have, in addition, focussed on minimizing computational effort by using metamodels (Youn et al. 2004; Kim and Choi 2008; Zhao et al. 2009; Zhu et al. 2009; Lönn et al. 2010; Wiebenga et al. 2011). The use of metamodels is one of the most promising techniques in order to minimize computational effort in stochastic optimization of large-scale problems.

\subsection{Scope of work}

The work presented in this thesis is a part of the research project 'Robust and multidisciplinary optimization of automotive structures' funded by Vinnova/ FFI. The primary aim of this project is to identify efficient methodologies for performing the robust and multidisciplinary design optimization of vehicle structures.

The primary aim of this study has been to develop efficient stochastic optimization methodologies for large-scale engineering applications.

The work has been conducted in three stages

- Identify and evaluate suitable, efficient, existing methods to perform stochastic analysis and stochastic design optimization of large-scale engineering structures.

- Develop new methodologies or modify existing methodologies to improve their performance and accuracy.

- Verify the capabilities of the developed methodologies using analytical examples and large-scale vehicle structural examples and compare their performance with traditional methods.

In Papers I and II emphasis is given to studying existing efficient methodologies and validating them using vehicle structural applications. In Papers III and $\mathbf{V}$ new stochastic optimization approaches are introduced. The capability of the approaches presented has been illustrated using engineering applications. In Paper III, an improved decoupled RBDO approach is presented, while in Paper $\mathbf{V}$ new sequential sampling approaches are proposed to improve the efficiency and accuracy of metamodel-based RBDO. In Paper IV, a study was made of the accuracy of existing simplified material scatter modelling methods in representing real material property variations. Material property variation is a crucial factor affecting the reliability of a structure. 


\subsection{Outline}

This thesis is organised as follows: Chapter 2 include a brief description of uncertainty types and uncertainty analysis methods. Chapter 3 gives an overview of the optimization formulations and genetic algorithms. Chapter 4 deals with metamodelling techniques and design of experiments. Chapter 5 gives a brief description of stochastic design optimization formulations and methods. In Chapter 6 the appended papers are reviewed. Finally, a discussion and conclusions drawn from the study are presented in Chapter 7. 


\section{Uncertainty analysis}

Most real-life engineering problems are non-deterministic, i.e. they involve uncertainties. In this section, a brief review of uncertainty types and some of the methods for uncertainty analysis are presented.

\subsection{Types of uncertainties}

Uncertainties can be categorized into aleatoric uncertainties, epistemic uncertainties and error or numerical uncertainties (Wojtkiewicz et al. 2001). Aleatoric uncertainties mainly arise due to variations in manufacturing processes, loading conditions or environmental factors etc. These uncertainties cannot be controlled or are too costly to control. If sufficient data is available, these uncertainties can be quantified in a statistical manner using probability distributions, e.g. variation in ambient temperature, sheet thickness, material properties, impact speed, impact angle, etc. Epistemic uncertainties occur mainly due to lack of knowledge about the system and variables, e.g. actual material properties, boundary conditions, etc. These uncertainties can be controlled. Numerical uncertainties primarily arise from the simulation environment due to various factors, e.g. numerical settings, software bugs or modelling error. These uncertainties are not directly related to design parameters.

\subsection{Material variations}

The variation in material properties is crucial for the reliability of a design. Consequently, it is necessary to represent the material property variation as close to the physically-observed variations as possible. For the purpose of this work the variation in plastic yielding was deemed to be of most interest. Plastic yielding affects the performance of both durability and crash safety.

In Paper IV, the accuracy of some existing material scatter modelling methods is studied by comparing the modelled plastic hardening variation with the variation of plastic hardening of a dual phase steel obtained by a series of tensile tests. 


\subsubsection{Strain hardening}

Stain hardening takes place when a metal is subjected to plastic deformation. A uniaxial tensile test is commonly used in order to determine the isotropic plastic hardening properties of a metal. However, standard tensile tests can only capture stress-strain relations accurately up to necking. Beyond necking, the hardening curve can be assessed by extrapolation with analytical expressions or by using inverse modelling to fit an analytical expression. Some common analytical expressions are

$$
\sigma_{f}\left(\bar{\varepsilon}^{p}\right)= \begin{cases}\sigma_{0}+K\left(\bar{\varepsilon}^{p}\right)^{n} & \text { Hollomon (1945) } \\ \sigma_{0}+K\left(1-e^{-A \bar{\varepsilon}^{p}}\right) & \text { Voce (1948) } \\ K\left(\varepsilon_{0}+\bar{\varepsilon}^{p}\right)^{n} & \text { Swift (1952) } \\ \sigma_{0}+K\left(1-e^{-A\left(\bar{\varepsilon}^{p}\right)^{n}}\right) & \text { Hockett and Sherby (1975) }\end{cases}
$$

where $\sigma_{0}$ is the initial yield stress, $\vec{\varepsilon}^{p}$ is the equivalent plastic strain, $K, n$ and $A$ are material parameters.

In Paper I, a modified Voce equation is used to fit the complete stress-strain data. Whereas in Paper IV, the Voce equation is used to fit the hardening curve up to diffuse necking and beyond the necking point the hardening curve is fitted using the Hollomon relation and inverse modelling, c.f. (Larsson et al. 2011). The reason for this approach is that the Voce hardening function yields a good fit up to necking. For higher plastic strains, however, this function saturates and experimental data shows that DP steels exhibit sustained hardening beyond necking, c.f. (Lee et al. 2005). The tensile test data which are used in this work are in the material rolling direction and an isotropic yield surface is assumed.

\subsection{Basic statistics}

In general, uncertainties are presented or quantified using probability distributions and the first two statistical moments, i.e. the mean and the variance. Some of the basic statistical terms used in this study are briefly described in this section, see Shafer and Zhang (2012) for more details. 


\subsubsection{Statistical terms}

The mean value, $\mu$, of a statistical entity is defined as

$$
\mu=\frac{1}{N} \sum_{i=1}^{N} x_{i}
$$

where $x_{i}$ is the $i^{t h}$ sample and $N$ is the total number of samples.

The variance, $V a r$, and the standard deviation, $\sigma$, are defined as

$$
\text { Var }=\sigma^{2}=\frac{1}{N-1} \sum_{i=1}^{N}\left(x_{i}-\mu\right)^{2}, \sigma=\sqrt{\operatorname{Var}}
$$

The standard deviation represents the dispersion of data from its mean. The lower the standard deviation, the closer the data points are to the mean.

The Pearson's correlation coefficient is widely utilized in order to represent the interdependency of two variables. The Pearson's correlation coefficient indicates the degree of linear relationship between two variables. The correlation coefficient, $r_{x y}$, between the variables $x$ and $y$ is defined by

$$
r_{x y}=\frac{\operatorname{Cov}(x, y)}{\sigma_{x} \sigma_{y}}=\frac{\sum_{i=1}^{N}\left(x_{i}-\bar{x}\right)\left(y_{i}-\bar{y}\right)}{\sqrt{\sum_{i=1}^{N}\left(x_{i}-\bar{x}\right)^{2}} \sqrt{\sum_{i=1}^{N}\left(y_{i}-\bar{y}\right)^{2}}}
$$

where $\bar{x}$ is the mean of $x, \bar{y}$ is the mean of $y$ and $\operatorname{Cov}(x, y)$ is the covariance between the variables $x$ and $y$.

The coefficient of correlation +1 indicates a perfect positive linear relationship, and the coefficient of correlation -1 indicates a perfect negative linear relationship. If the variables are independent, the coefficient of correlation is 0 .

\subsubsection{Distribution}

The probability distribution function (PDF) provides the relative frequency of occurrence of events. A short description of the two distributions used in this thesis is presented below.

\section{Normal distribution}

Normal distribution is the most commonly-used probability distribution, which most variations are assumed to follow. The probability density function (PDF) of a normal distribution is defined as

$$
f(x)=\frac{1}{\sigma \sqrt{2 \pi}} e^{-\frac{(x-\mu)^{2}}{\sigma^{2}}}
$$

If the distribution has $\mu=0$ and $\sigma=1$, then it is entitled standard normal distribution.

The cumulative distribution function (CDF) of the normal distribution is defined as

$$
F(x)=\int_{\infty}^{x} f(t) d t
$$


$F(x)$ is the probability of a value less than $x$.

\section{Uniform distribution}

In uniform distribution, also called rectangular distribution, each sample has an equal probability. The probability density function for a continuous uniform distribution on the interval $[a, b]$ is given by

$$
f(x)=\frac{1}{b-a} \quad \text { for } a \leq x \leq b
$$

\subsection{Uncertainty analysis}

Uncertainty analysis is performed to ascertain the statistical properties of the responses. Some of the methods are primarily used for reliability analysis and some are used for the evaluation of the first two statistical moments.

\section{Probability of failure}

The reliability of a system is measured in terms of probability of failure, i.e. the lower probability of failure the higher the reliability. A failure region is schematically shown in Figure 1. The load on the structure $X_{S}$ and the system resistance $X_{R}$ are random quantities. The probability densities of the $X_{S}$ and $X_{R}$ are $f_{S}\left(X_{S}\right)$ and $f_{R}\left(X_{R}\right)$ respectively. The shaded area represents the probability of failure where the load exceeds the resistance of the system. This is defined as

$$
P_{f}=P\left[X_{R}-X_{S} \leq 0\right]
$$

where $G=X_{R}-X_{S}$ is the limit state function.

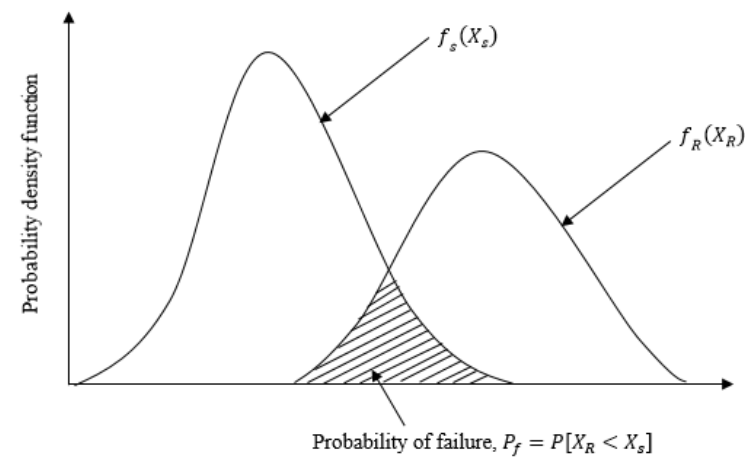

Figure 1: Probability of failure

If the vector of random variables is represented by $\mathbf{x}$ and the vector of random parameters by $\mathbf{z}$, the probability of failure is evaluated by an integral over the failure region as follows 


$$
P_{f}=P\left(\mathrm{~g}_{i}(\mathbf{x}, \mathbf{z}) \leq 0\right)=\int_{\mathrm{g}_{i}(\mathbf{x}, \mathbf{z}) \leq 0} f_{\mathrm{xz}}(\mathbf{x}, \mathbf{z}) d \mathbf{x} d \mathbf{z}
$$

where $f_{\mathrm{xz}}$ is the joint probability density function of all random variables and random parameters, and $\mathrm{g}_{i}(\mathbf{x}, \mathbf{z})$ is the $\mathrm{i}^{\text {th }}$ constraint function.

It is difficult, or in some cases impossible, to obtain an analytical solution to Equation (9) (Du and Chen 2000; Agarwal 2004). Consequently, simplifying analytical and sampling or simulation methods have been developed to provide approximate solutions. Analytical methods are simple and efficient, but require information about analytical sensitivities which are difficult to obtain for most complex problems. Simulation methods do not require analytical sensitivities and in general they are more accurate compared to analytical methods for problems with nonlinear limit state functions (Bichon et al. 2008). However, simulation methods are computationally expensive. In this section, relevant analytical and simulation methods are briefly described.

\subsubsection{Mean value first-order second-moment method (MVFSOM)}

This method requires only information regarding the first two statistical moments of random variables, i.e. the mean and variance. The mean and the variance of the limit state function are obtained by using a first order Taylor series approximation of the limit state function centred at the mean values of the random variables. The probability of failure is approximated using the mean and the standard deviation of the limit state function. Assuming $\mathbf{g}(\mathbf{x}, \mathbf{z})$ is normally distributed, the probability of failure is defined as

$$
P_{f}=\mathrm{g}(\mathrm{g} \leq 0)=\Phi\left(\frac{0-\mu_{\mathrm{g}}}{\sigma_{\mathrm{g}}}\right)
$$

which can be re-written as

$$
P_{f}=\Phi(-\beta)
$$

where $\Phi($.$) is the standard normal cumulative distribution function, \mu_{\mathrm{g}}$ and $\sigma_{\mathrm{g}}$ are the mean and standard deviation of the limit state function $\mathrm{g}$, and $\beta$ is termed the reliability index. The latter is defined as the ratio of the mean to the standard deviation of the limit state function

$$
\beta=\frac{\mu_{\mathrm{g}}}{\sigma_{\mathrm{g}}}
$$

The reliability index represents the distance from the limit state surface to the mean in terms of the number of standard deviations. The higher the value of $\beta$, the smaller the probability of failure. When evaluated using this method, the probability of failure is only accurate when the limit state function is linear and random variables are normally distributed, see (Haldar and Mahadevan 2000) for more details. 


\subsubsection{MPP-based methods}

One of the drawbacks of the MVFOSM method is that the reliability index varies depending on the problem formulation (Haldar and Mahadevan 2000). To overcome this, Hasofer and Lind (1974) proposed a concept of the most probable point (MPP) of failure for the reliability analysis. In this method, input variables are transformed into a standard normal space, i.e. input variables $\mathbf{x}=\left\{x_{1}, x_{2}, x_{3} . . x_{n}\right\}$ are transformed into an uncorrelated standard normal space $\mathbf{u}=\left\{u_{1}, u_{2}, u_{3} . . u_{n}\right\}$, and the reliability index $\beta$ is defined as the minimum distance from the failure surface $g(\mathbf{u})=0$ to the mean, i.e. the origin of the standardized space. The minimum distance point on the limit state surface is called the most probable point (MPP) of failure, see Figure 2.

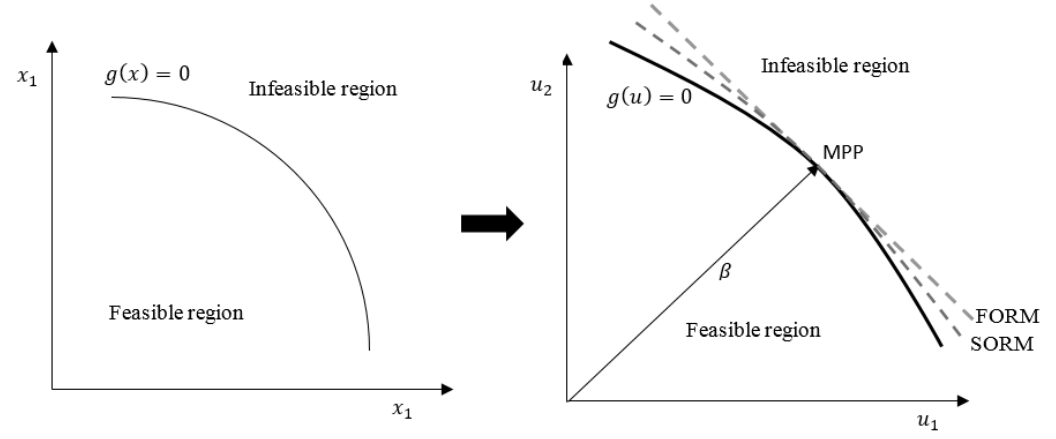

Figure 2: Most probable point

The first-order reliability method (FORM) and the second-order reliability method (SORM) are two widely used MPP-based methods. In FORM (Haldar and Mahadevan 2000), the linear approximation probability of failure is evaluated at the MPP. The MPP is obtained by the following optimization

$$
\begin{array}{ll}
\min & \|\mathbf{u}\| \\
\text { s.t. } & \mathrm{g}(\mathbf{u})=0
\end{array}
$$

where $\|$.$\| stands for the norm (length) of a vector. The reliability index \beta$ is given by $\|\mathbf{u}\|_{\min }$ and the probability of failure becomes

$$
P_{f} \approx \Phi(-\beta)
$$

The above approach is referred to as reliability index approach (RIA). Tu et al. (1999) proposed an alternative formulation referred to as performance measure approach (PMA), 
which is found to be efficient and stable compared to RIA. In this method, the MPP on the target reliability surface is identified using the following optimization formulation

$$
\begin{array}{ll}
\min & \mathrm{g}(\mathbf{u}) \\
\text { s.t. } & \|\mathbf{u}\|=\beta_{T}
\end{array}
$$

where $\beta_{T}$ is the target reliability. This approach is also called the inverse MPP approach. Since FORM uses a linear approximation at the MPP, it might give inaccurate results for highly non-linear limit state functions. To enhance the accuracy of the approximation the SORM has been proposed (Breitung 1984). In this method, the limit state function at the MPP is approximated using a quadratic surface. The probability of failure using the SORM is expressed as

$$
P_{f} \approx \Phi(-\beta) \prod_{i=1}^{n-1} 1+\beta \kappa_{i}^{1 / 2}
$$

where $\kappa_{i}$ denotes the main curvature of limit state function $\mathrm{g}(\mathbf{u})$ at the MPP.

\subsubsection{Monte Carlo simulation}

A Monte Carlo simulation (MCS) is an approximate method to evaluate the probability of failure and the statistical moments using a large number of experiments. This method is simple and reasonably accurate for a large sample size. MCS is based on two mathematical theorems: the law of large numbers and the central limit theorem. Repeated random sampling and function evaluation are carried out in this method and the probability of failure is estimated as

$$
P_{f}=P\left(\mathrm{~g}_{i}(\mathbf{x}, \mathbf{z}) \leq 0\right)=\frac{1}{N} \sum_{j=1}^{N} I\left[\left(\mathrm{~g}_{i}\left(x_{j}, z_{j}\right)\right]\right.
$$

where $N$ is the sample size, $x_{j}$ and $z_{j}$ are the samples of $\mathbf{x}$ and $\mathbf{z}$. I is an indicator function which is defined as

$$
I\left[\left(\mathrm{~g}_{i}(\mathbf{x}, \mathbf{z})\right]=\left\{\begin{array}{lr}
1 & \text { if } \mathrm{g}_{i}(\mathbf{x}, \mathbf{z}) \leq 0 \\
0 & \text { otherwise }
\end{array}\right.\right.
$$

The MCS can also be used in order to estimate the mean and the variance of a performance function. The mean and the variance of the performance function for $N$ samples is defined by

$$
\begin{aligned}
& \hat{\mu}_{\mathrm{g}_{i}}=\frac{1}{N} \sum_{j=1}^{N} \mathrm{~g}_{i}\left(x_{j}, z_{j}\right) \\
& \hat{\sigma}_{\mathrm{g}_{i}}^{2}=\frac{1}{N} \sum_{j=1}^{N}\left(\mathrm{~g}_{i}\left(x_{j}, z_{j}\right)-\mu_{\mathrm{g}_{i}}\right)^{2}
\end{aligned}
$$

The MCS method does not require information regarding analytical sensitivities. However, it is computationally expensive due to the large number of function evaluations required. Conventional MCS uses random sampling technique to select the samples. To minimize the computational effort of the MCS methods, more efficient sampling methods such as importance sampling (Engelund and Rackwitz 1993; Du and Chen 2000) and Latin hypercube sampling (McKay et al. 2000) have been reported in literature. In the importance 
sampling method, the samples around the MPP are selected for the MCS, thus reducing the number of samples required.

\subsubsection{Latin hypercube sampling}

Latin hypercube sampling (LHS) method is a constrained random sampling technique in which the statistical distribution of a random variable is divided into $N$ partitions with equal probability and samples are picked from each interval randomly. An illustration of the LHS method for a single variable $x$ is shown in Figure 3. The probability density function of variable $x$ is shown in Figure $3 \mathrm{a}$ and the cumulative distribution of the variable $x$ is shown in Figure 3b. The red dots show examples of sample locations. The vertical line shows the division of the PDF into areas of equal probability.

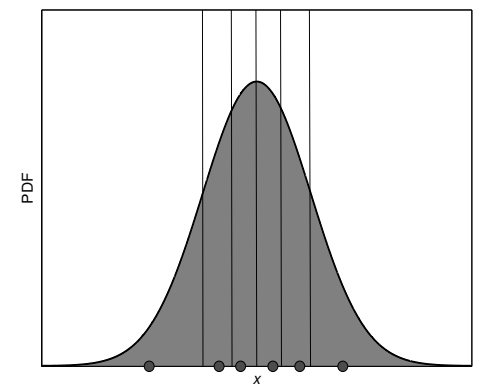

(a)

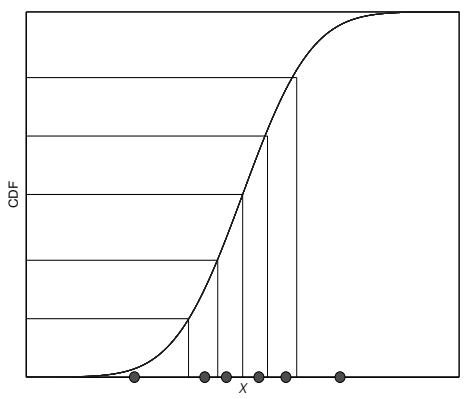

(b)

Figure 3: Illustration of Latin hypercube sampling for a normally distributed variable. 


\subsubsection{Worst-case approach and moment matching formulation}

In the worst-case approach (Parkinson et al. 1993), tolerances of input variables are used to estimate the variation of constraint function. A first-order Taylor series expansion is used to evaluate the constraint function variation, which can be formulated as

$$
\Delta \mathrm{g}_{i}=\sum_{j=1}^{n}\left|\frac{\partial \mathrm{g}_{\mathrm{i}}}{\partial x_{j}} \Delta x_{j}\right|+\sum_{j=1}^{m}\left|\frac{\partial \mathrm{g}_{\mathrm{i}}}{\partial z_{j}} \Delta z_{j}\right|
$$

The probabilistic constraint is defined in the deterministic format

$$
\mathrm{g}_{\mathrm{i}}-k \Delta \mathrm{g}_{\mathrm{i}} \geq 0
$$

where $\mathrm{g}_{\mathrm{i}}$ is the $\mathrm{i}^{\text {th }}$ constraint function, $\Delta x_{j}$ is the tolerance of $\mathrm{j}^{\text {th }}$ design variable, $\Delta z_{j}$ is the tolerance of the $\mathrm{j}^{\text {th }}$ random parameter and $k$ is the feasibility index.

In reality, the worst-case for all input variables might not occur simultaneously and often the worst-case method will result in conservative designs. This method can be used in situations when probability distribution of the random variable and random parameters are not available.

Unlike the worst-case approach, in a moment matching formulation the variance of input variables is used instead of tolerance values. For this case Equation (21) becomes

$$
\sigma_{g_{i}}^{2}=\sum_{j=1}^{n}\left(\frac{\partial \mathrm{g}_{\mathrm{i}}}{\partial x_{j}} \sigma_{x_{j}}\right)^{2}+\sum_{j=1}^{m}\left(\frac{\partial \mathrm{g}_{\mathrm{i}}}{\partial z_{j}} \sigma_{z_{j}}\right)^{2}
$$

and the constraint becomes

$$
\mathrm{g}_{\mathrm{i}}-k \sigma_{g_{i}} \geq 0
$$




\section{Structural optimization}

Design optimization is a process of finding optimal designs by selecting suitable design parameters that lead to the optimum performance under given constraints. In general, deterministic conditions are assumed for the optimization and this is referred to as deterministic optimization. Relevant optimization formulations are given in this section.

\subsection{Single objective optimization}

The mathematical formulation of a typical single objective optimization problem is expressed as

$$
\begin{array}{ll}
\text { Min } & f(\mathbf{x}, \mathbf{z}) \\
\text { S.t. } & \mathrm{g}_{\mathrm{i}}(\mathbf{x}, \mathbf{z}) \geq 0, i=1 \ldots m \\
& x_{i}^{L}<x_{i}<x_{i}^{U} \\
& \mathbf{x}=\left[x_{1}, x_{2}, x_{3} \ldots x_{n}\right] \\
& \mathbf{z}=\left[z_{1}, z_{2}, z_{3} \ldots z_{n}\right]
\end{array}
$$

where $f(\mathbf{x}, \mathbf{z})$ is the objective function and $\mathrm{g}_{\mathrm{i}}$ is the $i^{\text {th }}$ constraint function and $m$ is the number of constraints. $x_{i}^{L}$ and $x_{i}^{U}$ are the lower and upper limits, respectively, of the design variable $x_{i} . \mathbf{x}$ is the vector of design variables, and $\mathbf{z}$ is the vector of design parameters whose values are fixed as a part of the problem specification. The values of design parameters are fixed in the optimization problem, whereas values of design variables can be selected within the specified limit. The design variables are also termed as controllable variables. In real world engineering problems, both design parameters and design variables might contain uncertainties.

\subsection{Multiobjective optimization}

If the optimization process involves more than one objective it is termed multiobjective optimization. Multiobjective optimization can be expressed as 
Min

$$
\left[f_{1}(\mathbf{x}, \mathbf{z}), f_{2}(\mathbf{x}, \mathbf{z}), \ldots f_{k}(\mathbf{x}, \mathbf{z})\right]
$$

S.t.

$$
\begin{aligned}
& \mathrm{g}_{\mathrm{i}}(\mathbf{x}, \mathbf{z}) \geq 0, i=1 \ldots m \\
& x_{i}^{L}<x_{i}<x_{i}^{U} \\
& \mathbf{x}=\left[x_{1}, x_{2}, x_{3} \ldots x_{n}\right] \\
& \mathbf{z}=\left[z_{1}, z_{2}, z_{3} \ldots z_{n}\right]
\end{aligned}
$$

where $\left[f_{1}(\mathbf{x}), f_{2}(\mathbf{x}), \ldots f_{k}(\mathbf{x})\right]$ are the $k$ objective functions, $g_{i}$ is the $i^{t h}$ constraint function and $m$ is the number of constraints.

More often the multiobjective problems consist of conflicting objectives. In this case the optimization results in more than one optimal solution, which are non-dominated. These non-dominated solutions are termed the Pareto optimal solutions, see Figure 4. In this case, the goal is to find a trade-off between the conflicting objectives.

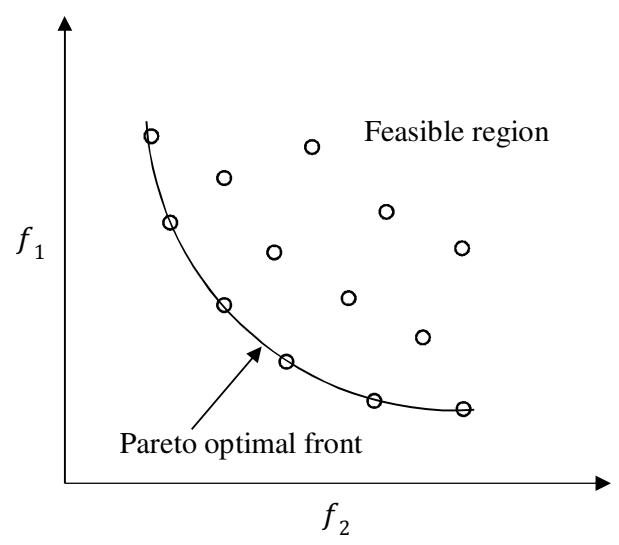

Figure 4: Pareto optimal solutions of a problem with two objective functions

\subsection{Multidisciplinary optimization}

Multidisciplinary optimization (MDO) involves more than one discipline i.e. objectives and variables, loads and constraints from relevant disciplines are considered in the optimization 
of a system. In addition, interdisciplinary coupling is considered. This optimization will produce an improved optimum design in a global sense, since it balances attributes from different disciplines. The MDO approach is gaining attention in the automotive industry, since most systems in vehicle engineering need to fulfil performance requirements related to different disciplines, e.g. crash, durability, NVH etc. Performing multidisciplinary optimization can also help in reducing total design cycle time. See Ryberg (2013) for more details on MDO.

\subsection{Optimization algorithms}

Several optimization algorithms have been developed over the years to solve a variety of optimization problems. These algorithms can be divided into gradient-based and nongradient based algorithms. Gradient-based algorithms require gradient information and generally a fewer number of function evaluations to reach an optimum compared to nongradient based algorithms. However, in many nonlinear applications, e.g. vehicle crash applications, gradients are difficult or impossible to evaluate. Furthermore, gradient methods require multiple starting points to obtain the global optimum. Non-gradient based algorithms do not require gradient information and some of them are more likely to identify a global optimum.

Non-gradient based stochastic algorithms have been widely used to solve complex optimization problems. Stochastic algorithms include simulated annealing (van Laarhoven and Aarts 1987), evolutionary algorithms (Fonseca and Fleming 1995), particle swarm optimization (Eberhart and Kennedy 1995), etc. These algorithms are typically inspired by physical or natural phenomena. Genetic algorithms, evolutionary strategy and evolutionary programming are the main types of evolutionary algorithms. Genetic algorithms have proven to perform well in solving multiobjective optimization problems and therefore genetic algorithms have been used in this work. However, these algorithms require a large number of function evaluations and are too costly to be used on the original optimization problem, as will be further explained.

Genetic algorithms (GA) are inspired by Darwin's principle of survival of the fittest. These algorithms mainly consist of four steps namely selection, reproduction, evaluation and replacement. The first step is to select the individuals for reproduction, each individual selected is referred to as a chromosome, which is represented by design variables called genes. In the next step, individuals with better fitness are generated using reproduction techniques, such as mating and crossover. The fitness of newly-created chromosomes are evaluated and these candidates replace the candidates with lower fitness from the initial population. This process is repeated until a termination criteria is satisfied. A schematic representation of the genetic algorithm process is shown in Figure 5. 


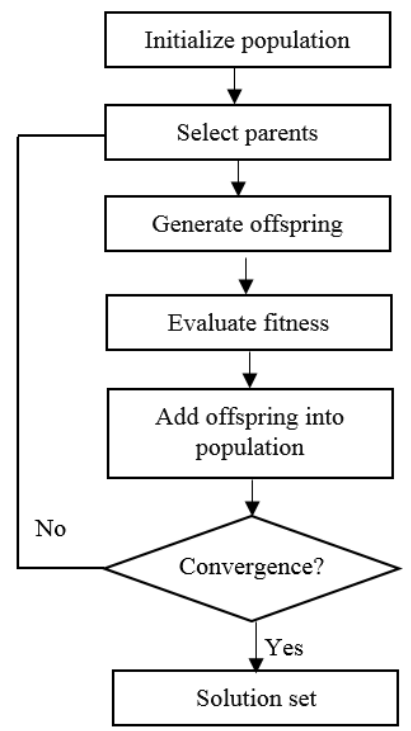

Figure 5: Genetic algorithm process

Multiobjective genetic algorithms MOGA (Fonseca and Fleming 1993) and NSGA -II (Deb et al. 2002) have been used in the present studies. Both the aforementioned algorithms are an extension of a genetic algorithm and use a non-dominated sorting approach to generate the Pareto front. 


\section{Metamodel-based design optimization}

Despite advancements in computer capacity and improved numerical algorithms, the computational effort required to perform the optimization of complex problems is still high. In automotive engineering, an increase in computational effort is partly due to the use of very detailed FE models, which are used to capture physical effects accurately. Metamodels, sometime termed surrogate models, are used in the engineering field to minimize computational effort. Metamodels are mathematical functions which approximate the original response function based on a few, computationally expensive, evaluations of the response function at selected design points. Once the metamodels are constructed, the approximated response at any sample location can be evaluated using these models. A general form of a metamodel is

$$
y(\mathbf{x})=\hat{y}(\mathbf{x})+\varepsilon
$$

where $\mathrm{y}(\mathbf{x})$ is the true response, $\hat{y}(\mathbf{x})$ is the approximated response by a metamodel, and $\varepsilon$ represents the approximation error and random error.

\subsection{Design of experiments}

Design points for the construction of metamodels should be selected so that the maximum information is extracted from the smallest set of samples. The procedure to determine the location of the design points is referred to as design of experiments (DOE). Several DOE strategies have been reported in literature. In this thesis, conventional Latin hypercube sampling (LHS) (McKay et al. 2000), see Section 2.4, and optimal Latin hypercube sampling (OLHS) have been used. The OLHS gives a better spread of the samples in the design space compared to the LHS. The OLHS selects the samples from the LHS set using an entropy criterion or the maximin distance approach (Johnson et al. 1990). The samples generated using LHS and OLHS using the maximin distance approach for a twodimensional space are presented in Figure 6. 


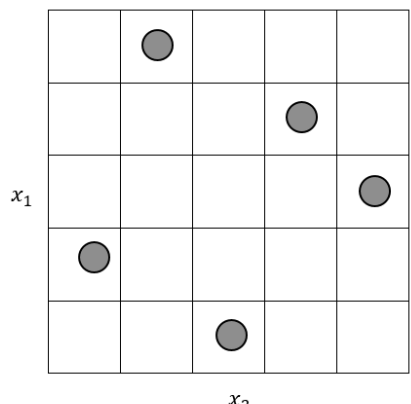

$x_{2}$

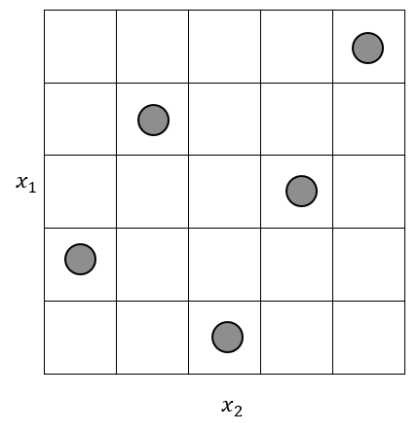

$x_{2}$

Figure 6: Samples generated using LHS and OLHS methods in the two-dimensional design space

\subsection{Metamodelling techniques}

Numerous different metamodelling techniques are available in literature. The metamodelling techniques employed in this work are reviewed in the section below.

\subsubsection{Polynomial regression}

The method with polynomial response surfaces also called polynomial regression (PR) models, (Myers et al. 2009) is one of the simplest and most widely-used metamodel techniques. A second-order polynomial model is expressed as

$$
y_{i}=\beta_{o}+\sum_{j}^{m} \beta_{j} x_{i j}+\sum_{j}^{m} \beta_{i j} x_{i j}^{2}+\sum_{j}^{m-1} \sum_{k=j+1}^{m} \beta_{j k} x_{i j} x_{i k}+\varepsilon_{i}, i=1, \ldots n
$$

where $x_{i j}$ is the $j^{\text {th }}$ design variable at the $i^{\text {th }}$ design point, $m$ is the number of design variables, $n$ is the number of design points, $\mathcal{E}_{i}$ is the error at $i^{\text {th }}$ design point, and $\beta_{j k}$ are the unknown regression coefficients.

Equation (27) can be written in matrix notation as

$$
\mathbf{y}=\mathbf{X} \boldsymbol{\beta}+\boldsymbol{\varepsilon}
$$

The regression coefficients $\boldsymbol{\beta}$ are solved by using the least square method which minimizes the error $\boldsymbol{\varepsilon}$.

$$
\boldsymbol{\beta}=\left(\mathbf{X}^{\mathrm{T}} \mathbf{X}\right)^{-1} \mathbf{X}^{\mathrm{T}} \mathbf{y}
$$


The minimum number of samples required to solve regression coefficients for a quadratic polynomial is $(n+1)(n+2) / 2$, where $n$ is the number of variables. However, $50 \%$ oversampling is often recommended (Redhe et al. 2002).

\subsubsection{Radial basis function}

The radial basis function (RBF) was originally developed for scattered multivariate data interpolation (Hardy 1971). The RBF is a linear combination of a series of basis functions, which are symmetric and centred around the sampling point.

The RBF can be written as

$$
\hat{y}=\sum_{i=1}^{n} \lambda_{i} \phi\left(\left\|\mathbf{x}-\mathbf{x}_{\mathbf{i}}\right\|\right)
$$

where $\phi$ is a basis function, $\mathbf{x}$ is the vector of design variables at the current location and $\mathbf{X}_{\mathbf{i}}$ is the vector of design variables at the $i^{\text {th }}$ sample point. $\left\|\mathbf{x}-\mathbf{x}_{\mathbf{i}}\right\|$ is the Euclidean distance between $\mathbf{x}$ and $\mathbf{x}_{\mathbf{i}}, \lambda_{t}$ is a weighting coefficient at the $i^{t h}$ design point and $n$ is the number of sampling points. The weighting coefficients can be solved using the sampled data points. In this thesis, Hardy's multiquadratic function is used as the basis function

$$
\phi(r)=\sqrt{r^{2}+c^{2}}, \quad 0<\mathrm{c} \leq 1
$$

For additional details on RBF models, see (Fang et al. 2005; Ryberg et al. 2012).

\subsubsection{Artificial neural network}

A typical artificial neural network (ANN) has a number of interconnected processing units called neurons or nodes, which are organised in the form of layers. Each neuron acts as a small computational unit which receives inputs from the neurons in the previous layer. These inputs are multiplied by the respective connection weight values and the weighted sum is then transferred through the activation function of the neuron to generate an output. The output from that neuron is fed as input to other neurons in the front layer as directed by the structure of the network. Layers in between input and output layers are known as hidden layers. A schematic representation of a typical neuron is shown in Figure 7.

The output $y_{k}$ from the $k^{\text {th }}$ neuron is evaluated as

$$
y_{k}=f\left(\sum_{i=1}^{n} w_{k i} x_{i}+b_{k}\right)
$$

where $f$ is the activation function, $x_{i}$ is the $\mathrm{i}^{\text {th }}$ input, $w_{k i}$ is the weight of the corresponding input $x_{i}$ for neuron $k$ and $b_{k}$ is the bias value. 


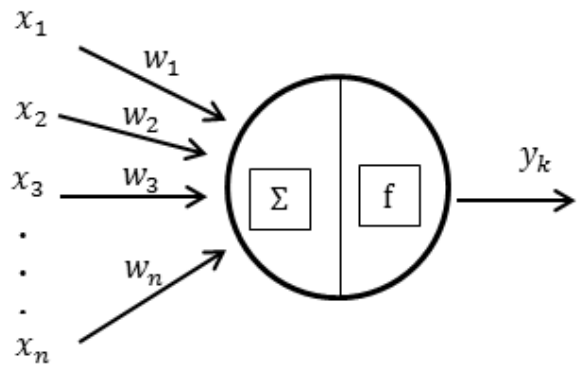

Figure 7: Artificial neuron

The architecture of the neural network determines the arrangement of the neurons and the flow of information through the structure. In this study, feed forward neural network (FFNN) is used as an architecture type. In FFNN the information flows in only one direction, i.e. no information travels backwards in the network.

The activation function $f$ uses some algorithms to process the input. One of the commonlyused activation functions is the sigmoid. The sigmoid function is defined as

$$
f(x)=\frac{1}{1+e^{-x}}
$$

In general, backward propagation algorithms are used to train the FFNN. This algorithm uses supervised learning, which requires a set of inputs and their corresponding outputs. The procedure starts with an estimation of the output by assigning random weights to connection and the estimation error is propagated backwards. Finally, these weights are adjusted so that the estimation error is minimized. For additional details on ANN models, see (Ryberg et al. 2012) .

\subsubsection{Kriging}

The Kriging response function is expressed as a combination of polynomial function and a stochastic process.

$$
y(\mathbf{x})=f(\mathbf{x})+z(\mathbf{x})
$$

where $y(\mathbf{x})$ is the deterministic response, $f(\mathbf{x})$ is a known polynomial function, and $z(\mathbf{x})$ represents the lack of fit of the metamodel. $z(\mathrm{x})$ is a random process assumed to have a zero mean, variance $\sigma^{2}$ and a non-zero covariance. The covariance function is given by

$$
C\left[z\left(\mathbf{x}_{i}\right), z\left(\mathbf{x}_{j}\right)\right]=\sigma^{2} R\left(\mathbf{x}_{\boldsymbol{i}}, \mathbf{x}_{\mathbf{j}}\right)
$$


$z\left(\mathbf{x}_{i}\right), z\left(\mathbf{x}_{j}\right)$ are vectors of the design variables at the $i^{t h}$ and $j^{t h}$ design points, respectively, and $R\left(\mathbf{x}_{i}, \mathbf{x}_{j}\right)$ is the correlation between $\mathbf{x}_{i}$ and $\mathbf{x}_{j}$. The Gaussian correlation function used in this study is expressed as

$$
R\left(\mathbf{x}_{i}, \mathbf{x}_{j}\right)=\exp \left[-\sum_{m=1}^{k} \theta_{m}\left|x_{i}^{m}-x_{j}^{m}\right|^{2}\right]
$$

where $\mathrm{x}_{i}^{m}$ and $\mathrm{x}_{j}^{m}$ are the $\mathrm{m}^{\text {th }}$ components of sample points $\mathbf{x}_{\boldsymbol{i}}$ and $\mathbf{x}_{\boldsymbol{j}}$, respectively, and $\theta_{m}$ is the correlation parameters for variable $x^{m}$. In isotropic Gaussian correlation, the same correlation parameter $\theta$ is used for all variables, whereas in anisotropic Gaussian correlation, different correlation parameters are used for each variable. More information regarding Kriging is found in (Simpson et al. 2001).

\subsection{Metamodel selection}

All metamodelling techniques have their advantages and disadvantages, there is no single metamodelling technique which is superior for all type of problems. Even in a single application, all responses may not be represented well with one metamodel type. Numerous studies (Jin et al. 2001; Jin et al. 2003; Fang et al. 2005; Yang et al. 2005) have compared the performance of metamodels concerning a variety of problems. Jin et al. (2001) have compared the performance of four metamodelling techniques PR, RBF, Kriging and Multivariate Adaptive Regression Splines (MARS) using different classes of problems. They found that the overall performance of RBF was better than the other models. However, for noisy problems Jin et al. (2001) recommended the PR model. Fang et al. (2005) compared PR and RBF models using vehicle crashworthiness optimization and found that RBF gave more accurate results compared to PR models. Five metamodelling techniques were studied by Yang et al. (2005) to approximate frontal impact crashworthiness performance. They concluded that no single metamodel stood out for a small sample size, i.e. for $\leq 9 N$ samples.

\subsection{Error measurements}

Three error metrics are employed in the work to measure the prediction accuracy of the metamodels: the coefficient of determination $R^{2}$, the root mean square error (RMSE) and $R M S E_{c v d}$, which is based on cross-validation errors.

$$
R^{2}=1-\frac{\sum_{i=1}^{N}\left(y_{i}-\widehat{y}_{l}\right)^{2}}{\sum_{i=1}^{N}\left(y_{i}-\bar{y}_{l}\right)^{2}}
$$




$$
\begin{gathered}
R M S E_{\text {actual }}=\sqrt{\frac{1}{N} \sum_{i=1}^{N}\left(y_{i}-\widehat{y}_{l}\right)^{2}} \\
R M S E_{c v d}=\sqrt{\frac{1}{N} \boldsymbol{\varepsilon}^{T} \boldsymbol{\varepsilon}}
\end{gathered}
$$

where $y_{i}$ is the evaluated response, $\widehat{y}_{l}$ is the approximated response by the metamodel at the $i^{\text {th }}$ design point, $\bar{y}$ is the mean value, and $N$ is the number of samples. $R M S E_{c v d}$ is evaluated using the cross-validation approach and $\boldsymbol{\varepsilon}=\hat{y}(\mathbf{x})-y(\mathbf{x})$ is the cross-validation error vector. The advantage of the $R M S E_{c v d}$ is that no additional validation points are required to evaluate the error. Cross validation errors are computed by excluding one point from the training set while creating the metamodel, and the point omitted is used to compute the cross-validation error (leave-one-out strategy). This process is repeated $N$ times to generate a vector of cross-validation errors), where $N$ is the total number of training points. $R^{2}$ indicates how well the metamodel is able to capture the variability in the response. A lower value of RMSE indicates better accuracy. 


\section{Stochastic optimization}

In conventional deterministic optimization, deterministic models and well-defined loads are considered for the optimization. However, most real-world problems are non-deterministic, i.e. they involve uncertainties. Optimum designs obtained without considering uncertainties, might become unreliable or non-robust when exposed to uncertainties, since optimization algorithms often tend to push the designs to the boundaries leaving little space for uncertainties. Consequently, stochastic optimization methods are increasingly used in order to identify reliable and robust optimal designs. The two main categories of stochastic optimization methods are reliability-based design optimization (RBDO) and robust design optimization (RDO).

\subsection{Reliability-based design optimization}

The main aim of the RBDO is to identify an optimum design that has a low probability of failure. The difference between a deterministic optimum design and a reliability-based optimum design is illustrated in Figure 8.

The mathematical formulation of a typical RBDO is

$$
\begin{array}{ll}
\text { Min } & f(\mathbf{x}, \mathbf{z}) \\
\text { S.t. } & \left.P\left(\mathrm{~g}_{i}(\mathbf{x}, \mathbf{z})\right) \geq 0\right) \geq R_{i}, i=1, \ldots n
\end{array}
$$

where $f$ and $g$ are the objective and constraint function, respectively. $\mu$ is the mean, $f$ is a function of $\mathbf{x}$, the vector of design variables, and $\mathbf{z}$, the vector design parameters whose values are fixed as a part of the problem specification, $n$ is the number of constraints and $R_{i}$ is the desired reliability level for the $i^{t h}$ constraint function. Methods to evaluate the constraint function are briefly studied in Section 2.4. Two types of constraint formulations have been used in this thesis. The first formulation is based on moment matching formulation (Parkinson et al. 1993) and it is given by

$$
\mu_{\mathrm{g}_{i}}-k \sigma_{\mathrm{g}_{i}} \geq 0
$$


where $k$ is the feasibility index, $\mu_{\mathrm{g}_{i}}$ is the mean and $\sigma_{\mathrm{g}_{i}}$ is the standard deviation of the $\mathrm{i}^{\text {th }}$ constraint function. Here, the mean and the standard deviation of the constraint functions are evaluated using the MCS method.

The second formulation is expressed as

$$
\begin{aligned}
& \left.P\left(\mathrm{~g}_{i}(\mathbf{x}, \mathbf{z})\right) \geq 0\right)=1-P_{f} \\
& \left.P_{f}=P\left(\mathrm{~g}_{i}(\mathbf{x}, \mathbf{z})\right) \leq 0\right)=\frac{1}{N} \sum_{j=1}^{N} I\left[\left(\mathrm{~g}_{i}\left(x_{j}, z_{j}\right)\right]\right.
\end{aligned}
$$

where $N$ is the sample size, $x_{j}$ and $z_{j}$ are the samples of $\mathbf{x}$ and $\mathbf{z}$. I is an indicator function, which is defined as

$$
I\left[\left(\mathrm{~g}_{i}(\mathbf{x}, \mathbf{z})\right]=\left\{\begin{array}{lr}
1 & \text { if } \mathrm{g}_{i}(\mathbf{x}, \mathbf{z}) \leq 0 \\
0 & \text { otherwise }
\end{array}\right.\right.
$$

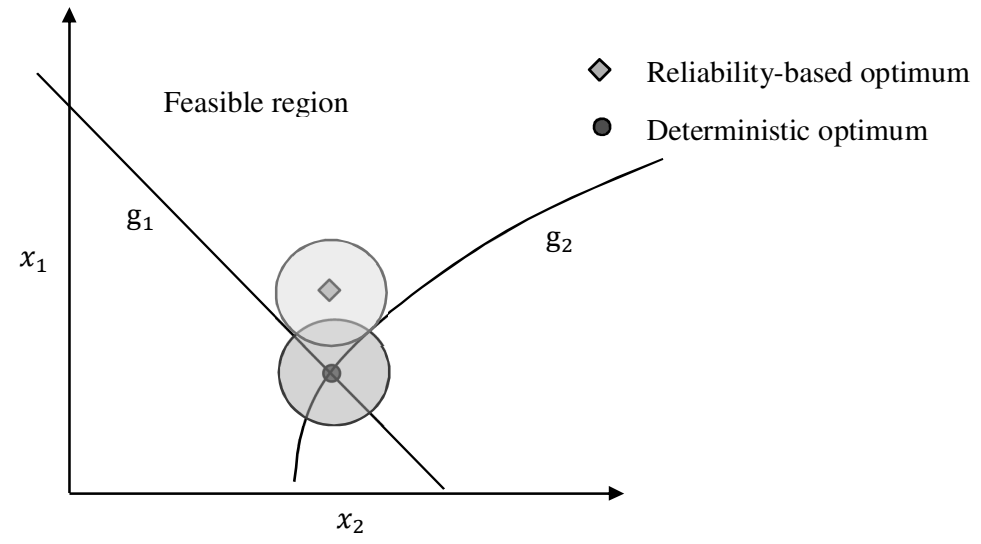

Figure 8: Deterministic optimum vs. Reliability-based optimum illustrated in the 2D design space

\subsection{Robust design optimization}

In a RDO method, both the mean and variance of the performance function are minimized while keeping constraint satisfaction at a target reliability level. The difference between a deterministic optimum design and a robust optimum design is shown in Figure 9. The mathematical formulation of a typical RDO is 


$$
\begin{array}{ll}
\text { Min } & {[\mu(f(\mathbf{x}, \mathbf{z})), \sigma(f(\mathbf{x}, \mathbf{z}))]} \\
\text { S.t. } & \left.P\left(\mathrm{~g}_{i}(\mathbf{x}, \mathbf{z})\right) \geq 0\right) \geq R_{i}
\end{array}
$$

where $\mu(f(\mathbf{x}, \mathbf{z}))$ and $\sigma(f(\mathbf{x}, \mathbf{z}))$ are the mean and standard deviation of the objective function $f$. These two objectives conflict with each other and an appropriate trade-off between them has to be made. In this thesis, RDO formulations from (Lee and Park 2001; Doltsinis and Kang 2004) have been used. The objective function in Equation (45) can be approximated as a weighted linear combination of the two objective functions, where the value of the weighting factor is based on the importance allocated to the minimization of the mean and variation of the system performance. Since the mean and standard deviations have different magnitudes, these are normalized using their corresponding values in the baseline design.

$$
\begin{array}{ll}
\text { Min } & {\left[\alpha \frac{\mu(f(\mathbf{x}, \mathbf{z}))}{\mu(f(\mathbf{x}, \mathbf{z}))^{*}}+(1-\alpha) \frac{\sigma(f(\mathbf{x}, \mathbf{z}))}{\sigma(f(\mathbf{x}, \mathbf{z}))^{*}}\right] \quad \alpha<0<1} \\
\text { S.t. } & \mu\left(\mathrm{g}_{i}(\mathbf{x}, \mathbf{z})\right)+k \sigma\left(\mathrm{g}_{i}(\mathbf{x}, \mathbf{z})\right) \leq 0
\end{array}
$$

$\alpha$ is the weighting factor, $\mu(f(\mathbf{x}, \mathbf{z})){ }^{*}$ and $\sigma(f(\mathbf{x}, \mathbf{z})){ }^{*}$ are the mean and the standard deviation, respectively, of the objective function of the baseline design.

$\diamond$ Robust optimum

- Deterministic optimum

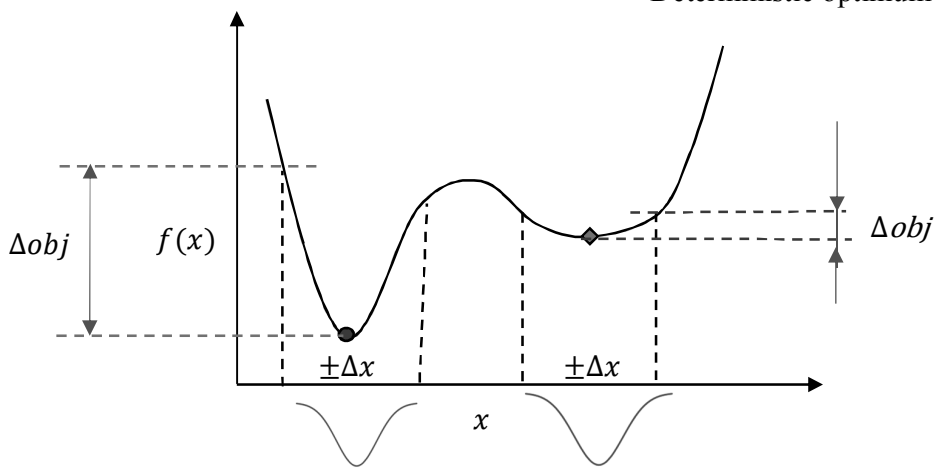

Figure 9: Deterministic optimum vs. Robust optimum 


\subsection{Reliability-based design optimization methods}

Traditionally, a double-loop method has been used to perform RBDO. Double-loop methods are computationally expensive and impractical for large-scale engineering problems. Many recent studies have focused on improving the efficiency of the double-loop process and developing new RBDO strategies. Some of them are briefly described in the following sections.

\subsubsection{Double-loop method}

The double-loop method consists of an inner loop that is used for the reliability analysis and an outer loop for the optimization. The outer loop selects the feasible samples iteratively based on the objective function value. Generally, MPP-based methods or simulation methods, see Section 2.4, are used for the reliability analysis. In order to minimize computational hardship, decoupled methods and single-loop methods have been developed.

\subsubsection{Decoupled methods}

In decoupled RBDO methods (Wu et al. 2001; Du and Chen 2004), deterministic optimization and reliability analysis are performed separately until convergence. In the first cycle, deterministic optimization is performed and in the second cycle violated constraints are shifted into the probabilistic feasible region using shifting factors, which are obtained by means of a reliability analysis at the end of the first cycle. The shifting factors are updated at the end of each optimization loop until the optimization converges. In general constraint shifting factors are evaluated using inverse MPPs of the constraint functions.

\subsubsection{Single-loop methods}

In single-loop approaches (Chen et al. 1997; Liang et al. 2004), the double-loop is converted into a single-loop equivalent to a deterministic optimization problem. This is realized by replacing the reliability analysis loop with equivalent Karush-Kuhn-Tucker (KKT) optimality conditions. Thus, the computational effort necessary to perform RBDO is minimized. 


\subsubsection{Metamodel-based RBDO}

An alternative method of realizing an efficient RBDO process is to employ metamodels to approximate the original FE models then the benefits of the double-loop method can be achieved but at lower computational cost. In recent years, several studies have been reported in literature regarding the application of metamodels for RBDO of large-scale engineering problems (Youn and Choi 2004; Müllerschön et al. 2007; Kim and Choi 2008; Chen et al. 2014; Li et al. 2016). Conventionally, the global metamodel or single-stage metamodel approach is used to perform RBDO (Jin et al. 2003; Gu et al. 2013; Shetty and Nilsson 2015). In this approach metamodels are fitted using design samples which have design variables and random parameters as input variables, i.e. the design space includes both design variables and random parameters. The disadvantage of this approach is that it requires a large number of function evaluations to increase the fidelity of the metamodels. However, increased sample size might not improve the local accuracy of the metamodel (Jin et al. 2003).

Previous studies have shown that the accuracy of metamodels for RBDO largely depends on the selection of design points (Lee and Jung 2008; Zhao et al. 2009; Chen et al. 2014). Consequently, several sampling strategies have been proposed in literature to improve the efficiency and accuracy of metamodel-based RBDO. Youn and Choi (2004) proposed a new metamodel-based approach based on the moving least square method especially for RBDO. The authors have integrated the hybrid mean value method (HMV) method proposed by Youn et al. (2003) with the metamodel. A selective sampling method is used to improve the accuracy of approximation in critical regions. A prediction interval of the metamodels was used by Kim and Choi (2008) to obtain a conservative optimum which compensates for the errors in the metamodels. Additional samples are added around MPPs for the active constraints in order to refine the metamodels. Zhao et al. (2009) proposed a sequential sampling strategy in which local metamodels are built around the current design. Samples are added in locations where the Kriging prediction error is large around the point of interest, which is in the vicinity of current design point. A constraint boundary sampling (CBS) method has been proposed by Lee and Jung (2008). In this approach, samples are located sequentially on the constraint boundaries using initial Kriging metamodels and the mean squared error (MSE) to improve accuracy near the constraint boundary. To further improve efficiency, Chen et al. (2014) proposed a sequential sampling method called the local adaptive sampling method (LAS), where samples are added around the current design point in each iteration. More samples are added near constraint boundaries in the neighbourhood of the current design point. Samples are added using the CBS method and the MSE criterion. An enhanced version of the LAS method is proposed by ( $\mathrm{Li}$ et al. 2016) in which samples are added in the vicinity of the MPP instead of current design, i.e. the MPP is used as the sampling center. MPPs of the active or violated constraints are considered for sampling. 


\subsection{Robust design optimization methods}

Genichi Taguchi (Taguchi 1993) originally introduced the concept of robust design. The main objective of Taguchi's method is to minimize performance variations caused by noise factors. Parameters that are difficult to control by the designer such as manufacturing variations, temperature, operating conditions, etc., are referred to as the noise factors and parameters that can be controlled by the designer to make the design robust are called the control factors. Taguchi proposed a concept of signal to noise ratio ( $\mathrm{S} / \mathrm{N}$ ratio) to measure robustness. This ratio provides the effects of noise factors on performance. The robustness of the design is improved by identifying the control factor settings that maximize the $\mathrm{S} / \mathrm{N}$ ratio. The DOE used in this method, called orthogonal arrays, consists of an inner array of control factors and an outer array of noise factors. For each control factor setting, the noise factors are changed systematically to evaluate the $\mathrm{S} / \mathrm{N}$ ratio. Although Taguchi's method is simple, it might lead to unnecessarily expensive experiments and non-optimal solutions (Tsui 1996). Taguchi's method was originally developed for experimental analysis and this method does not use a systematic optimization approach to obtain a robust design. In recent decades, advancements in simulation tools and computer power have made it possible to incorporate robustness analysis into simulation-based optimization. This is referred to as simulation-based RDO. The objective of the RDO is to optimize the mean performance function and minimize the performance variation, subject to probabilistic constraints, which ensures the reliability of the optimum design, see Section 5.2. In general, a Taylor series expansion or a simulation method is used in order to compute the mean and variance of the system performance. The commonly-used Taylor series methods includes worst-case approach and the moment matching method (Parkinson et al. 1993; Parkinson 1995; Zhang et al. 2007), see Section 2.4.

Metamodels have also been widely used in order to minimize the computational effort for RDO (Koch et al. 2004; Zhang et al. 2007; Lönn et al. 2010; Sun et al. 2011; Aspenberg et al. 2013; Gu et al. 2013; Shetty and Nilsson 2015). Conventionally used single-stage metamodel approaches (Gu et al. 2013; Shetty and Nilsson 2015) are simple and efficient. However, the accuracy of performance variation prediction is poor. Consequently, several alternative approaches have been proposed in literature. Sun et al. (2011) and Aspenberg et al. (2013) used dual response metamodels in order to improve the accuracy of estimation. In this approach, separate metamodels are constructed to represent the control space and the noise space respectively. Thus separate metamodels are constructed for the mean and the standard deviation of responses. However, dual response metamodels are expensive compared to the single-stage metamodel approach. Wiebenga et al. (2011) proposed a sequential robust optimization method in order to improve the accuracy of the objective function prediction by adding new samples in the optimum region. In this study the efficient improvement algorithm (EI) proposed by Jones et al. (1998) has been used to locate infill points for new samples. 


\section{Review of appended papers}

\section{Paper I}

\section{Robustness study of a hat profile beam made of boron steel subjected to three point bending}

In the first paper, an FE study of the robustness of a hat profile beam made from boron steel subjected to a three point bending load is presented, and an approach to incorporating the variations studied is demonstrated. Fracture risk factors and the maximum deflection of the beam are the measured responses. Spatial variation of the sheet thickness is considered in the forming simulations, along with other input variations. Stress-strain relations from tensile tests have been used in the robustness analyses to represent the variation in material properties. Furthermore, validation of four metamodeling techniques have been performed. Both the measured responses were found to be sensitive to input variations. Separate metamodels were constructed for each risk-prone zone of the structure in order to improve the performance of the metamodels for risk factor responses.

\section{Paper II}

\section{Multiobjective reliability-based and robust design optimization for crashworthiness of a vehicle side impact}

Optimized design using classical optimization techniques with deterministic models might not meet the desired performance level, or might fail in extreme events in real life due to uncertainties in design parameters and loading conditions. Consequently, it is essential to account for uncertainties in a systematic manner in order to generate a robust and reliable design. The second paper presents an approach to performing multiobjective reliabilitybased design optimization and robust design optimization. The method presented has been verified using a vehicle side impact crashworthiness application. The importance of a non- 
deterministic optimization approach as compared to a deterministic approach is illustrated by comparing the results from a non-deterministic optimization with those from a deterministic optimization. The approaches presented in the study were found to be suitable for applications related to vehicle structures.

\title{
Paper III
}

\section{Efficient, reliability-based optimization using a combined metamodel and FE-based strategy}

\begin{abstract}
Although single-stage metamodels are widely used to improve the efficiency of structural optimization, their accuracy is doubtful, especially in the case of reliability-based design optimization. The reason is that the accuracy of performance variation prediction by singlestage metamodels is poor. In the third paper an improved, decoupled sequential reliabilitybased optimization, using the combination of metamodel-based and FE-based strategy, is presented. In this study metamodels are used for the optimization only and the uncertainty analysis is carried out using an FE-based Monte Carlo simulation. The optimization and stochastic analysis loops are completely decoupled. Stochastic analysis is performed at the end of each optimization iteration and at the beginning of the first iteration only. In each optimization iteration, the standard deviation of the constraint functions from the previous iteration is used to update the probabilistic constraints.
\end{abstract}

\section{Paper IV}

\section{An evaluation of simple techniques to model the variation in strain- hardening behavior of steel}

Scatter in material properties is one of the main sources of uncertainty which needs to be accounted for in the stochastic design optimization of automotive body structures. However, it is expensive to quantify the scatter in material properties since this requires a considerable number of physical tests. Consequently, simplified scatter modelling methods have been used at early design stages in order to incorporate the material variations in stochastic optimization. In this work the accuracy of simplified material scatter modelling approaches is assessed in representing the physical behaviour of a material and its associated variation. The accuracy assessment is carried out by comparing the approximated material scatter data 
to detailed experimental scatter data. In addition, accuracy is assessed on a structural level by predicting the variation of the response of an axially crushed, thin-walled square tube made of dual phase steel DP600. In this study the focus is on an impact load case, since the impact load case is one of the most critical load cases in vehicle body structure development.

\section{Paper V}

\section{Two sequential sampling methods for metamodeling in reliability- based design optimization}

Metamodels are commonly used to overcome the drawback of the computational effort required to perform RBDO. The sampling strategy for the metamodels is a key issue for the efficiency and accuracy of the RBDO. Several sequential sampling strategies have been proposed in order to increase the accuracy of metamodels efficiently in the areas of interest, but most of these strategies depend on Kriging metamodels. In this paper, two new pragmatic sequential sampling methods, that are independent of the Kriging method, are proposed. In the first proposed method, a sequential deterministic optimization is performed and new samples are added around the deterministic optimum. Thus, the sample density near active constraint boundaries is increased. This method assumes that the reliable optimum lies in the vicinity of the deterministic optimum. Furthermore, an alternative slightly more expensive, but more robust, method is presented. In the second method, several optimum regions are identified and refined, which means that the chance of finding the global optimum increases compared to the first method. The computational capability of the proposed methods is illustrated using analytical examples and a multidisciplinary optimization of an automotive structure. The results show that the proposed methods are efficient and reasonably accurate. 


\section{Conclusions and outlook}

The main focus of this work has been to evaluate the capabilities of established approaches to performing design optimization under uncertainties, and to develop new improved methods that can handle the complex vehicle structural problems encountered in automotive product development.

The studies presented in Paper I and Paper II have shown that the computational cost can be reduced significantly by using metamodels for stochastic analysis and stochastic design optimization. Although the computational effort was significantly reduced by using metamodels, there were some issues identified regarding the accuracy of metamodels in predicting certain responses. It was found in Paper I that the metamodels which were employed could not predict the facture risk factor responses accurately since these are discontinuous. This problem has been solved to a certain extent by creating separate metamodels to represent the critical regions of the structure. However, this approach requires a prior knowledge of the risk-prone zones and, for some cases, a significant number of FE simulations might be required to acquire this knowledge. In Paper II, it was found that the overall accuracy of the single-stage (global) metamodels, which were used in this work, was acceptable for deterministic optimization. However, the accuracy of performance variation (i.e. standard deviation), prediction needs to be improved. Due to the poor prediction of the standard deviation, the optimum design obtained may become infeasible when validated using the detailed FE simulation if the constraints are active at the optimum. More than one optimal solutions might need to be verified to find a feasible optimum solution. The main advantage of single-stage metamodels is that they are simple to use and flexible, i.e. different optimization formulations can be evaluated using the same set of metamodels. If accuracy is not the primary concern, single-stage metamodels could be used for stochastic optimization by tightening the constraints to compensate for the metamodel prediction error.

The main focus of Paper III and Paper $\mathbf{V}$ has been to improve the accuracy of metamodelbased RBDO. The approach presented in Paper III is an improved, decoupled RBDO approach which utilises metamodels only for deterministic optimization. Uncertainty analysis is performed only at the end of each optimization cycle using FE simulations. The combined metamodel and FE-based strategy, used in this study improved efficiency 
compared to conventional double-loop methods and improved accuracy compared to the single-stage strategy. In Paper V, two new sequential sampling strategies for metamodelbased RBDO were proposed. Their efficiency comes from the fact that the accuracy of the metamodels is improved locally only in the critical regions. One of the main benefits of these methods is that they are not based on one particular type of metamodelling technique. In a complex engineering example, it is important to construct accurate metamodels efficiently for different types of responses. Consequently it is important to be able to freely choose any appropriate metamodel formulation. In this study, a model-independent crossvalidation error was used to measure the accuracy and a maximin distance approach was used to locate new samples.

Accurate representation of material uncertainties is important in order to obtain accurate stochastic analysis results. Due to lack of detailed data, simplified methods are often used at early design stages in order to model material scatter. In Paper IV, the accuracy of some commonly-used methods of representing the real material variation has been studied. The scaling of the nominal stress-strain curve based on the $\mathbf{R}_{\mathbf{m}}$ scatter was found to be a reasonable choice to model the material scatter, when limited material data is available. The recommended method represents the real material scatter well, as long as the workhardening behaviour of the material does not vary much as compared to the nominal hardening curve. For most steels the work-hardening behaviour does not change much within a given steel grade, c.f. (Even and Reichert 2010). However, for materials in which work-hardening behaviour is not consistent, this method might not give accurate results. If the scatter data of the strain-hardening exponent is available, the material scatter can be represented reasonably well by independently varying the parameters of a power law hardening relation.

Results from Paper II, show that vehicle body structures from the advanced stages of product development are relatively robust. Due to the use usage of high safety factors, the robustness of the structures improves over the product development period. However, this performance robustness often affects weight efficiency negatively. In general, these safety factors are primarily based on experience and not on the effects of actual input uncertainties. Consequently it is desirable to perform stochastic analysis at early phases of the design development process in order to gain more insight into the effect of uncertainties on performance. This knowledge will help designers to create better designs and will minimize computational effort required in later stages to make the designs reliable. In Paper II, only one load case, a side impact, was considered for the optimization, but other load cases such as roof crush performance might have been affected due to the changes of the design variables. In order to achieve a balanced design, it is important to consider all influenced load cases in the optimization. 
As a consequence, in Paper $\mathbf{V}$, durability and crashworthiness load cases were considered while optimizing the load net bracket. Both durability and crashworthiness performance were affected due to changes in the design of the bracket.

Although metamodels have proven to be effective for a variety of responses, their ability to approximate discontinuous responses must still be improved. Further research is required to improve the accuracy of metamodels in representing discontinuous responses, in order to enable the application of the methods developed to problems with discontinuous responses.

In this study, examining the accuracy of simplified material scatter modelling method simulation results from an impact load case is considered. It would be interesting to perform a similar study using other types of load cases in order to check whether the methods recommended are also valid for other types of load cases.

Another interesting strategy which has not been studied in this thesis is combining the single-stage metamodel approach with the conservative metamodelling technique which was presented in (Picheny et al. 2008). This approach may be used when accuracy is not the primary concern. This approach enables the advantages of the global metamodels. 


\section{Bibliography}

Agarwal H (2004) Reliability based design optimization: formulations and methodologies. $\mathrm{PhD}$ Thesis, University of Notre Dame.

Aspenberg D, Nilsson L, Jergeus J (2013) Robust optimization of front members in a full frontal car impact, Engineering Optimization, 45(3), 245-264.

Bichon BJ, Eldred MS, Swiler LP, Mahadevan S, McFarland JM (2008) Efficient global reliability analysis for nonlinear implicit performance functions, AIAA Journal, 46(10), 2459-2468.

Breitung K (1984) Asymptotic approximations for multinormal integrals, Journal of Engineering Mechanics, 110(3), 357-366.

Chen X, Hasselman TK, Neill DJ (1997) Reliability based structural design optimization for practical applications, In: Proceedings of the $38^{\text {th }}$ AIAA/ASME/ASCE/AHS/ASC structures, structural dynamics, and materials conference, Florida, USA.

Chen Z, Qiu H, Gao L, Li X, Li P (2014) A local adaptive sampling method for reliabilitybased design optimization using Kriging model, Structural and Multidisciplinary Optimization, 49(3), 401-416.

Deb K, Pratap A, Agarwal S, Meyarivan T (2002) A fast and elitist multiobjective genetic algorithm: NSGA-II, IEEE Transactions on Evolutionary Computation, 6(2), 182197.

Doltsinis I, Kang Z (2004) Robust design of non-linear structures using optimization methods, Computer Methods in Applied Mechanics and Engineering, 193(23-26), 2221-2237.

Du X, Chen W (2000) Towards a better understanding of modeling feasibility robustness in engineering design, ASME Journal of Mechanical Design, 122(4), 385-394.

Du X, Chen W (2004) Sequential optimization and reliability assessment method for efficient probabilistic design, Journal of Mechanical Design, 126(2), 225-233.

Eberhart R, Kennedy J (1995) A new optimizer using particle swarm theory, In: Proceedings of the Sixth International Symposium on Micro Machine and Human Science, IEEE.

Engelund S, Rackwitz R (1993) A benchmark study on importance sampling techniques in structural reliability, Structural safety, 12(4), 255-276.

Even D, Reichert B (2010) A pragmatic strategy to take into account metal materials scatter in FEA, In: Proceedings of 9th German LS-DYNA Forum, Bamberg, Germany.

Fang H, Rais-Rohani M, Liu Z, Horstemeyer MF (2005) A comparative study of metamodeling methods for multiobjective crashworthiness optimization, Computers \& Structures, 83(25-26), 2121-2136. 
Fonseca CM, Fleming PJ (1993) Genetic algorithms for multiobjective optimization: formulation discussion and generalization, In: Fifth International Conference on Genetic Algorithms, San Mateo, California, USA.

Fonseca CM, Fleming PJ (1995) An overview of evolutionary algorithms in multiobjective optimization, Evolutionary computation, 3(1), 1-16.

Gu X, Sun G, Li G, Mao L, Li Q (2013) A comparative study on multiobjective reliable and robust optimization for crashworthiness design of vehicle structure, Structural and Multidisciplinary Optimization, 48(3), 669-684.

Haldar A, Mahadevan S (2000) Probability, Reliability and Statistical Methods in Engineering Design, John Wiley, New York.

Hardy RL (1971) Multiquadric equations of topography and other irregular surfaces, Journal of geophysical research, 76(8), 1905-1915.

Hasofer AM, Lind NC (1974) Exact and invariant second-moment code format, Journal of the Engineering Mechanics Division, 100(1), 111-121.

Jin R, Chen W, Simpson TW (2001) Comparative studies of metamodelling techniques under multiple modelling criteria, Structural and Multidisciplinary Optimization, 23(1), 1-13.

Jin R, Du X, Chen W (2003) The use of metamodeling techniques for optimization under uncertainty, Structural and Multidisciplinary Optimization, 25(2), 99-116.

Johnson ME, Moore LM, Ylvisaker D (1990) Minimax and maximin distance designs, Journal of Statistical Planning and Inference, 26(2), 131-148.

Jones DR, Schonlau M, Welch WJ (1998) Efficient global optimization of expensive blackbox functions, Journal of Global Optimization, 13(4), 455-492.

Kim C, Choi KK (2008) Reliability-based design optimization using response surface method with prediction interval estimation, Journal of Mechanical Design, 130(12), 121401.

Koch P, Yang R-J, Gu L (2004) Design for six sigma through robust optimization, Structural and Multidisciplinary Optimization, 26(3-4), 235-248.

Larsson R, Björklund O, Nilsson L, Simonsson K (2011) A study of high strength steels undergoing non-linear strain paths-experiments and modelling, Journal of Materials Processing Technology, 211(1), 122-132.

Lee K-H, Park G-J (2001) Robust optimization considering tolerances of design variables, Computers \& Structures, 79(1), 77-86.

Lee M-G, Kim D, Kim C, Wenner ML, Chung K (2005) Spring-back evaluation of automotive sheets based on isotropic-kinematic hardening laws and non-quadratic anisotropic yield functions, part III: applications, International Journal of Plasticity, 21(5), 915-953.

Lee TH, Jung JJ (2008) A sampling technique enhancing accuracy and efficiency of metamodel-based RBDO: Constraint boundary sampling, Computers \& Structures, 86(13), 1463-1476.

Li X, Qiu H, Chen Z, Gao L, Shao X (2016) A local Kriging approximation method using MPP for reliability-based design optimization, Computers \& Structures, 162, 102115.

Liang J, Mourelatos ZP, Tu J (2004) A single-loop method for reliability-based design optimization, In: ASME 2004 International Design Engineering Technical Conferences and Computers and Information in Engineering Conference, Salt Lake City, USA. 
Lönn D, Fyllingen $\varnothing$, Nilssona L (2010) An approach to robust optimization of impact problems using random samples and meta-modelling, International Journal of Impact Engineering, 37(6), 723-734.

McKay MD, Beckman RJ, Conover WJ (2000) A comparison of three methods for selecting values of input variables in the analysis of output from a computer code, Technometrics, 42(1), 55-61.

Myers RH, Montgomery DC, Anderson-Cook CM (2009) Response surface methodology: process and product optimization using designed experiments, Wiley, NewYork.

Müllerschön H, Lorenz D, Roll K (2007) Reliability based design optimization with LSOPT for a metal forming application, In: Proceedings of 6th German LS-DYNA Forum Frankenthal, Germany.

Parkinson A (1995) Robust mechanical design using engineering models, Journal of Mechanical Design, 117, 48-54.

Parkinson A, Sorensen C, Pourhassan N (1993) A general approach for robust optimal design, Journal of Mechanical Design, 115(1), 74-80.

Picheny V, Kim N-H, Haftka RT, Queipo NV (2008) Conservative predictions using surrogate modeling, In: Proceedings of the 49th AIAA/ASME/ASCE/AHS/ASC structures, structural dynamics, and materials conference, Illinois, USA.

Redhe M, Forsberg J, Jansson T, Marklund PO, Nilsson L (2002) Using the response surface methodology and the D-optimality criterion in crashworthiness related problems, Structural and Multidisciplinary Optimization, 24(3), 185-194.

Ryberg A-B (2013) Metamodel-based design optimization: a multidisciplinary approach for automotive atructures. Licentiate thesis, Linköping University.

Ryberg A-B, Domeij Bäckryd R, Nilsson L (2012) Metamodel-based multidisciplinary design optimization for automotive applications ,Techincal Report LIU-IEI-R12/003, Linköping University. Linköping

Shafer DS, Zhang Z (2012) Introductory Statistics, Flat World Knowledge.

Shan S, Wang GG (2008) Reliable design space and complete single-loop reliability-based design optimization, Reliability Engineering \& System Safety, 93(8), 1218-1230.

Shetty S, Nilsson L (2015) Multiobjective reliability-based and robust design optimisation for crashworthiness of a vehicle side impact, International Journal of Vehicle Design, 67(4), 347-367.

Simpson TW, Poplinski JD, Koch PN, Allen JK (2001) Metamodels for computer-based engineering design: survey and recommendations, Engineering with Computers, $17(2), 129-150$.

Sun G, Li G, Zhou S, Li H, Hou S, Li Q (2011) Crashworthiness design of vehicle by using multiobjective robust optimization, Structural and Multidisciplinary Optimization, 44(1), 99-110.

Taguchi G (1993) Taguchi on robust technology development. bringing quality engineering upstream, ASME press, New York.

Tsui K-L (1996) A critical look at Taguchi's modelling approach for robust design, Journal of Applied Statistics, 23(1), 81-96.

Tu J, Choi KK, Park YH (1999) A new study on reliability-based design optimization, Journal of Mechanical Design, 121(4), 557-564.

van Laarhoven PJM, Aarts EHL (1987) Simulated annealing: theory and applications, Springer Netherlands, Dordrecht. 
Wiebenga J, Klaseboer G, Van Den Boogaard A (2011) Efficient robust optimization of metal forming processes using a sequential metamodel based strategy, In: The 8th International Conference and Workshop on numerical simulation of $3 D$ seet metal forming processes, Seoul, South Korea.

Wojtkiewicz SF, Eldred MS, Field RV, Urbina A, Red-Horse JR (2001) Uncertainty quantification in large computational engineering models. Sandia National Laboratories, Albuquerque, USA.

Wu Y, Shin Y, Sues R, Cesare M (2001) Safety-factor based approach for probability-based design optimization, In: Proc. 42nd AIAA/ASME/ASCE/AHS/ASC Structures, Structural Dynamics, and Materials Conference, number AIAA-2001-1522, Seattle, Washington, USA.

Yang RJ, Wang N, Tho CH, Bobineau JP, Wang BP (2005) Metamodeling development for vehicle frontal impact simulation, Journal of Mechanical Design, 127(5), 10141020.

Youn BD, Choi KK (2004) A new response surface methodology for reliability-based design optimization, Computers \& Structures, 82(2-3), 241-256.

Youn BD, Choi KK, Park YH (2003) Hybrid analysis method for reliability-based design optimization, Journal of Mechanical Design, 125(2), 221-232.

Youn BD, Choi KK, Yang RJ, Gu L (2004) Reliability-based design optimization for crashworthiness of vehicle side impact, Structural and Multidisciplinary Optimization, 26(3-4), 272-283.

Zhang Y, Zhu P, Chen G (2007) Lightweight design of automotive front side rail based on robust optimisation, Thin-Walled Structures, 45(7-8), 670-676.

Zhao L, Choi KK, Lee I, Du L (2009) Response surface method using sequential sampling for reliability-based design optimization, In: ASME International Design Engineering Technical Conferences and Computers and Information in Engineering Conference, California, USA.

Zhu P, Zhang Y, Chen G (2009) Metamodel-based lightweight design of an automotive front-body structure using robust optimization, Proceedings of the Institution of Mechanical Engineers, Part D: Journal of Automobile Engineering, 223(9), 11331147. 


\section{Papers}

The articles associated with this thesis have been removed for copyright reasons. For more details about these see:

http://urn.kb.se/resolve?urn=urn:nbn:se:liu:diva-133199 